Full-length article

\title{
Establishment and characteristics of two syngeneic human osteosarco- ma cell lines from primary tumor and skip metastases ${ }^{1}$
}

\author{
Chang-ye ZOU ${ }^{2}$, Jin $\mathrm{WANG}^{2}$, Jing-nan $\mathrm{SHEN}^{2,6}$, Gang HUANG${ }^{2}$, Song $\mathrm{JIN}^{2}$, Jun-qiang $\mathrm{YIN}^{2}$, Qian-chen GUO ${ }^{2}$, Hao-miao \\ $\mathrm{LI}^{2}$, Lan $\mathrm{LUO}^{3}$, Meng $\mathrm{ZHANG}^{4}$, Long-juan $\mathrm{ZHANG}^{5}$ \\ ${ }^{2}$ Department of Musculoskeletal Oncology, ${ }^{3}$ Medical Central Laboratory, ${ }^{4}$ Department of Pathology and ${ }^{5}$ Surgery Laboratory, First Affiliated Hospital of \\ Sun Yat-Sen University, Guangzhou 510080, China
}

\section{Key words}

skip metastasis; osteosarcoma; Zos; Zos-M

${ }^{1}$ Project supported by the National Natural Science Foundation of China (№ 30200285) and the Sun Yat-Sen University 5010 grant.

${ }^{6}$ Correspondence to Prof Jing-nan SHEN.

Phn 86-20-8775-5766, ext 8898

Fax 86-20-8733-2150.

E-mail shenjingnan@21cn.com

Received 2007-07-24

Accepted 2007-10-29

doi: 10.1111/j.1745-7254.2008.00756.x

\begin{abstract}
Aim: To characterize and compare the different biological behaviors of 2 novel human osteosarcoma cell lines, Zos and Zos-M, established respectively from the primary tumor and the skip metastasis of an osteosarcoma patient. Methods: In vitro studies included morphological observations, karyotype analysis, 3-(4,5-dimethylthiazol-2-yl)-2,5-diphenyltetrazolium bromide cell proliferation assay, and cell sensitivity to chemotherapeutic drugs. Subcutaneous and intravenous inoculations into nude mice were carried out to study the tumorigenicity and the metastatic potential. RT-PCR was performed to assess the expression of the osteoblastic markers and some metastasis-related genes. Results: Both cell lines remained stable for more than 100 passages in vitro without interruption. The RT-PCR examination indicated that they retained the molecular characteristics of an osteoblastic lineage. The karyotype analysis displayed aneuploidy and various structural abnormalities. Both cell lines are tumorigenic; Zos-M differs from Zos by the former's ability to develop lung metastasis after intravenous injection. The comparison of the expression patterns of some metastasis-related genes revealed that the decreased expression of cadherin-11 in Zos-M may correlate with a high potential of metastases. Moreover, both cell lines are less sensitive to the current chemotherapy protocols. Conclusion: The establishment of osteosarcoma cell lines, Zos and Zos-M, and related animal models provide a useful resource for studying the aggressive behavior of osteosarcoma and will be helpful for screening effective treatment strategies.
\end{abstract}

\section{Introduction}

Osteosarcoma is the most common primary malignant bone tumor in children and adolescents. It accounts for $20 \%$ of the malignant tumors of children ${ }^{[1]}$. During the past 3 decades, the 5-year survival rate has improved significantly to $60 \%-70 \%{ }^{[2]}$ as a result of the extensive application of multi-agent chemotherapy. However, more than $30 \%$ of patients still suffer medical failure, mostly because of relapse and metastases ${ }^{[3]}$. Skip metastasis is defined as a second focus of osteosarcoma, anatomically separated from the primary tumor, which is found in the same bone or on the opposite side of the adjacent joint ${ }^{[4]}$. Patients with skip metastasis suffer more from medical failure, the prognosis of which is parallel or even worse than those with lung metastasis ${ }^{[5-7]}$. Until now, little has been known about the intramedullary dissemination of osteosarcoma.

Cell lines and clinically-relevant animal models provide important resources for investigating tumor molecular pathology and evaluating new therapy strategies ${ }^{[8-12]}$. The established osteosarcoma cell lines, especially those with tumorigenic and metastatic potential, play a considerable role in the discovery and function analysis of the molecular events of tumor development and metastasis ${ }^{[12,13-16]}$. Up until now, many osteosarcoma cell lines with different background have been developed, but most of them are not tumorigenic, and even fewer can metastasize ${ }^{[11]}$. To our knowledge, no cell lines originating from skip metastasis have been reported. 
Two novel human osteosarcoma cell lines, Zos and Zos-M, were established respectively from the primary tumor and the skip lesion of an 18-year-old male patient. The purpose of the current study is to investigate the characteristics of these 2 cell lines, including drug sensitivity, so as to provide useful tools for the study of osteosarcoma. Biological behaviors and the expression of a small panel of metastasis-related genes were also compared between the 2 cell lines to find out potential molecular events that may contribute to the dissemination of osteosarcoma.

\section{Material and methods}

Animals and drugs Male BALB/c nude mice (4-6 weeks) were obtained from the Experimental Animal Department of Sun Yat-Sen University (Guangzhou, China) and raised in a sterile condition with constant temperature and humidity. All animal experimental protocols were approved by the Animal Care and Use Committee of Sun YatSen University.

Methotrexate (MTX) and 3-(4,5-dimethylthiazol-2-yl)2,5-diphenyltetrazolium bromide (MTT) were purchased from Sigma (St Louis, MO, USA). Doxorubicin (ADM) and cisplatin (DDP) were purchased from the National Institute for the Control of Pharmaceutical and Biological Products (Beijing, China).

Cell source and culture An 18-year-old boy suffered continuous pain in his right knee for 3 months. A needle biopsy confirmed the diagnosis of osteoblastic osteosarcoma in January 2005. After 2 cycles of chemotherapy using the protocols ADM, DDP, MTX, isofosfamide, alternatively, the boy rejected the operation. During the following 4 months, the tumor aggravated quickly and reached $40 \mathrm{~cm} \times$ $30 \mathrm{~cm} \times 10 \mathrm{~cm}$ in size. Hip disarticulation was performed in August 2005, and lung metastasis were detected by X-ray photography 1 month later. Three months later, the patient died of tumor dissemination. Two osteosarcoma specimens were obtained, respectively, from the primary tumor in the right distal femoral extremity and skip metastasis in the right femoral head. Informed consent for the experimental use of the specimens was obtained from the patient and his parents.

Parts of the specimens were fixed for pathological examinations and other parts were rinsed several times with phosphate-buffered saline (PBS) containing penicillin G $(100 \mathrm{U} / \mathrm{mL})$ and streptomycin $(100 \mathrm{mg} / \mathrm{mL})$. The tumor fragments were then minced into small pieces, approximately $1 \mathrm{~mm}^{3}$ in size, and seeded into screw-top culture flasks (Corning Costar, Corning, NY, USA) moistened with medium. The culture flasks were inverted and cultured at
$37{ }^{\circ} \mathrm{C}$ in a $5 \% \mathrm{CO}_{2}$ incubator for $2 \mathrm{~h}$, allowing adherence of the explants to the bottom. They were then turned over and a small amount of Dulbecco's modified Eagle's medium (DMEM; high glucose, GIBCO, Invitrogen, Carlsbad, CA, USA) containing $10 \%$ fetal bovine serum (FBS; GIBCO, InvitrogenCarlsbad, CA, USA ), penicillin $\mathrm{G}(100 \mathrm{U} / \mathrm{mL})$, streptomycin $(100 \mathrm{mg} / \mathrm{mL})$, and L-glutamine $(2 \mathrm{mmol} / \mathrm{L})$ were added. Two days later, a few polygonal cells outgrew the explants. Over the next few days, the long-spindleshaped fibroblasts outgrowing beside the tumor cells were labeled and scraped off. Twelve days later, the cells reached confluence and were dispersed by PBS containing $0.25 \%$ trypsin and $0.02 \%$ EDTA. The cell suspensions were transferred to new culture flasks to form monolayer cultures. The cells were maintained in the same medium and passaged every $3 \mathrm{~d}$.

The human osteosarcoma cell line U-2OS was a gift from Dr M SERRA (Istituti Ortopedici Rizzoli, Bologna, Italy). It was cultured in DMEM supplemented with $10 \%$ FBS at $37{ }^{\circ} \mathrm{C}$ in a $5 \% \mathrm{CO}_{2}$ incubator. The normal osteoblastic cell line hFOB1.19 (expressing SV40 large T antigen) used for comparison was originally obtained from the American Type Culture Collection (Manassas, VA, USA). It was cultured in a 1:1 mixture of Ham's F12 medium and DMEM without phenol red and with $2.5 \mathrm{mmol} / \mathrm{L}$ L-glutamine and $0.3 \mathrm{mg} / \mathrm{mL} \mathrm{G} 418$.

Morphological observations The morphology of the living cells in the culture flasks were observed under an inverted microscope (Olympus CKX31, Olympus, Tokyo, Japan) and pictures were taken.

The cells for the transmission electron microscope examination were prepared as described previously ${ }^{[10]}$. Briefly, the cells were first fixed in $2.5 \%$ glutaraldehyde in $67 \mathrm{mmol} / \mathrm{L}$ phosphate buffer $(\mathrm{pH} 7.4)$ and then in $1 \% \mathrm{OsO}_{4}$ in $67 \mathrm{mmol} / \mathrm{L}$ phosphate buffer. Both steps were done at $4{ }^{\circ} \mathrm{C}$ for $30 \mathrm{~min}$. Next, the specimens were dehydrated in a graded series of ethanol concentrations and embedded in Epon 812. Ultra-thin sections were cut and mounted on nickel mesh grids. The sections were stained with uranyl acetate and lead citrate and were examined with a transmission electron microscope (Hitachi H-800, Tokyo, Japan).

Proliferation and chemosensitivity assay The cells in the logarithmic growth phase were harvested and seeded into 6-well plates (Corning Costar, USA) with 5000 cells per well. Every day for $7 \mathrm{~d}$, the cells in 3 wells were harvested and counted with trypan blue. The experiment was repeated 3 times. Growth curves were then drawn and the doubling time was calculated according to the logarithmic phase of the growth curve. 
The sensitivity of MTX was expressed as the ratio of the concentration resulting in $50 \%$ inhibition of growth $\left(\mathrm{IC}_{50}\right)$ of the cell lines. To determine the $\mathrm{IC}_{50}$ values, 5000 cells per well were seeded in triplicate on a 96-well plate with DMEM containing $10 \%$ FBS. The medium was also added to the wells without cells as the blank control. After $24 \mathrm{~h}$, the medium in each well was replaced with 180 $\mu \mathrm{L}$ DMEM containing 10\% FBS and no MTX (control) or with different concentrations of MTX. The MTT assay was done by adding $20 \mu \mathrm{L}$ MTT $(5 \mathrm{mg} / \mathrm{mL})$ into each well $96 \mathrm{~h}$ later. After incubation at $37^{\circ} \mathrm{C}$ for an additional $4 \mathrm{~h}$, the medium was replaced with $150 \mu \mathrm{L}$ DMSO to dissolve the formazan that had precipitated. Then the absorbance was measured at $490 \mathrm{~nm}$ in a microtiter plate reader (elx 800 BIO-TEK, Winooski, VT, USA). The percentages of growth inhibition compared with the appropriate control were estimated and the $\mathrm{IC}_{50}$ values were calculated from the cytotoxicity curves (Bliss's software,Bliss Co, CA, USA). The sensitivity of the other drugs was evaluated as described for MTX. Data shown is representative of 3 independent experiments; values presented are the mean \pm SD. Statistical significance was determined by Student's $t$-test using Microsoft Excel software (Microsoft, Redmond,WA USA). A 2 -side $P$-value of $<0.01$ was considered statistically significant.

Matrigel invasion assay The transwell chamber with polycarbonate filters ( 8 um pore size; Costar, Cambridge, MA, USA) coated with the artificial basement membrane matrigel (12.5 $\mu \mathrm{g}$ per filter; Becton Dickinson Labware, Waltham, MA, USA) were used to detect the invasive ability of the Zos and Zos-M cell lines. In total, $1 \times 10^{5}$ cells in $0.1 \mathrm{~mL}$ serum-free medium were seeded in the upper chamber, and $0.6 \mathrm{~mL}$ medium with $15 \%$ FBS was added to the lower chamber. After incubation at $37{ }^{\circ} \mathrm{C}$ in $5 \% \mathrm{CO}_{2}$ for $24 \mathrm{~h}$, non-invading cells in the upper chamber were wiped completely clean with a cotton swab, then the filters were fixed with $10 \%$ formalin for 10 min and washed with PBS. The cells were stained with hematoxylin and rinsed with water. The number of cells migrating on the lower surface of the filters was counted under a microscope in 5 random high-power fields per membrane. Each assay was performed in triplicate.

Tumorigenicity and experimental metastasis assay The cells at the sixteenth passage in the exponential phase were harvested, washed with serum-free medium, and counted. The cells $\left(5 \times 10^{6}\right)$ were suspended in $0.2 \mathrm{~mL}$ PBS and were injected subcutaneously near the scapula of 6 nude mice for each cell line. Each week, the tumor size was measured with a sliding caliper. Two months later, the mice were killed and the tumors were fixed with $10 \%$ formaldehyde and embedded in wax. The sections stained with hematoxylin-eosin were used for pathological examination. The lung and liver were treated similarly for the detection of metastases.

Both of the in vitro passaged osteosarcoma cell cultures were harvested and prepared for injection as described above. The cells were brought to a final concentration of 1 $\times 10^{7}$ cells $/ \mathrm{mL}$ in PBS. An aliquot $(200 \mu \mathrm{L})$ of cell suspensions was injected into the tail vein of each nude mouse, and 8 nude mice were used for each cell line. Eight weeks later, the mice were killed and the lung and liver were fixed for the detection of metastases.

Chromosomal analysis The passaged cells in the exponential phase of growth were incubated with colchicine (Sigma, Saint Quentin Fallavier, France) at a final concentration of $0.8 \mu \mathrm{g} / \mathrm{mL}$ for $4 \mathrm{~h}$ and harvested. The cells were then treated with a hypotonic solution of potassium chloride $(0.075 \mathrm{~mol} / \mathrm{L})$ and incubated at $37{ }^{\circ} \mathrm{C}$ for $30 \mathrm{~min}$. The cells were then fixed in acetic acid, methanol (1:3, $v$ : $v$ ), mounted on grease-free, cooled slides, and air dried. Giemsa trysin banding was performed for the chromosome examination.

RNA extraction and RT-PCR Total RNA was extracted from cells using TRIZOL (Invitrogen, Carlsbad, CA, USA) according to the product instructions. The extracted RNA was quantitated by spectrophotometry and examined using $1.2 \%$ agarose gel (Biowest, Spain) electrophoresis. First-strand cDNA was synthesized with $1 \mu \mathrm{g}$ of total RNA and a first-strand cDNA synthesis kit (Toyobo, Osaka, Japan) according to the manufacturer's protocol. The genes tested included osteogenic-related genes osteocalcin, osteopontin, alkaline phosphatase (ALP), and tumor invasiveness-related genes vil2, cadherin-11, Fas, CD44 neurofibromin 2 (NF2), and breast cancer metastasis suppressor 1 (BRMS1). The primer sequences and product sizes are listed in Table 1. Amplification was performed for 25 cycles to avoid saturation in a $25 \mu \mathrm{L}$ reaction volume. For $\beta$-actin, ALP, osteopontin, ezrin, cadherin-11, and $\mathrm{CD} 44$ each cycle included $30 \mathrm{~s}$ at $94{ }^{\circ} \mathrm{C}, 30 \mathrm{~s}$ at $56^{\circ} \mathrm{C}$, and $30 \mathrm{~s}$ at $72^{\circ} \mathrm{C}$. For BRMS1 and Fas, it included $30 \mathrm{~s}$ at $94^{\circ}$ $\mathrm{C}, 30 \mathrm{~s}$ at $60^{\circ} \mathrm{C}$, and $30 \mathrm{~s}$ at $72{ }^{\circ} \mathrm{C}$. For osteocalcin, it included $30 \mathrm{~s}$ at $94{ }^{\circ} \mathrm{C}, 30 \mathrm{~s}$ at $62{ }^{\circ} \mathrm{C}$, and $30 \mathrm{~s}$ at $72{ }^{\circ} \mathrm{C}$. For $\mathrm{NF} 2$, it included $30 \mathrm{~s}$ at $94{ }^{\circ} \mathrm{C}, 30 \mathrm{~s}$ at $63{ }^{\circ} \mathrm{C}$, and $30 \mathrm{~s}$ at $72{ }^{\circ} \mathrm{C}$. The amplification products were electrophoresed in a $2 \%$ agarose gel containing $0.3 \mu \mathrm{g} / \mathrm{mL}$ ethidium bromide and were observed under UV light.

\section{Results}

Morphology by light microscopy and electron microscopy The cells showed a heterogeneous appearance 
Table 1. Primer sequences and product sizes.

\begin{tabular}{|c|c|c|}
\hline Gene & Primer sequence & Fragment size \\
\hline$\beta$-actin & $\begin{array}{l}\text { Forward: 5'-GTGGGGCGCCCCAGGCACCA-3' } \\
\text { Reverse: 5'-GTCCTTAATGTCACGCACGATTTC-3' }\end{array}$ & 539 \\
\hline$A L P$ & $\begin{array}{l}\text { Forward: 5'-ACGTGGCTAAGAATGTCATC-3' } \\
\text { Reverse: 5'-CTG GTA GGC GAT GTC CTT A-3' }\end{array}$ & 475 \\
\hline Osteocalcin & $\begin{array}{l}\text { Forward: 5'-ATGAGAGCCCTC ACA CTC CTC-3' } \\
\text { Reverse: 5'-GCC GTA GAA GCG CCG ATA GGC-3' }\end{array}$ & 293 \\
\hline Osteopontin & $\begin{array}{l}\text { Forward: 5'-CCAACTAAGTCCAACGAA AG-3' } \\
\text { Reverse: 5'-GGT GAT GTC CTC GTC TGT A-3' }\end{array}$ & 347 \\
\hline Vil-2 & $\begin{array}{l}\text { Forward: 5'-AGGAAGCCTGACACCATC-3' } \\
\text { Reverse: 5'-TGCTGCCACTCTTCAACT-3' }\end{array}$ & 457 \\
\hline BRMS1 & $\begin{array}{l}\text { Forward: 5' - ACTGAGTCAGCTGCGGTTGCGG-3' } \\
\text { Reverse: 5'-AAGACCTGGAGCTGCCTCTGGCGTGC-3' }\end{array}$ & 334 \\
\hline Cadherin-11 & $\begin{array}{l}\text { Forward: 5'-CACCGTGGTTGGGAGA-3' } \\
\text { Reverse: 5'-AAACTTGGGCGCATTATCG-3' }\end{array}$ & 267 \\
\hline$C D 44$ & $\begin{array}{l}\text { Forward: 5'-CTCACATCCAACACCTCCCAGTAT-3' } \\
\text { Reverse: 5'-TCAGTAGGGTTGCTGGGGTAGAT-3' }\end{array}$ & 205 \\
\hline Fas & $\begin{array}{l}\text { Forward: 5'-GCCAATTCTGCCATAAGCCCTGTCC-3' } \\
\text { Reverse: 5'-GCTGGTGAGTGTGCATTCCTTGAT-3' }\end{array}$ & 316 \\
\hline$N F 2$ & $\begin{array}{l}\text { Forward: 5'-ATGGTACAGGGCACTCGC-3' } \\
\text { Reverse: 5'-GGACAAGGGCAACAGCAA-3' }\end{array}$ & 356 \\
\hline
\end{tabular}

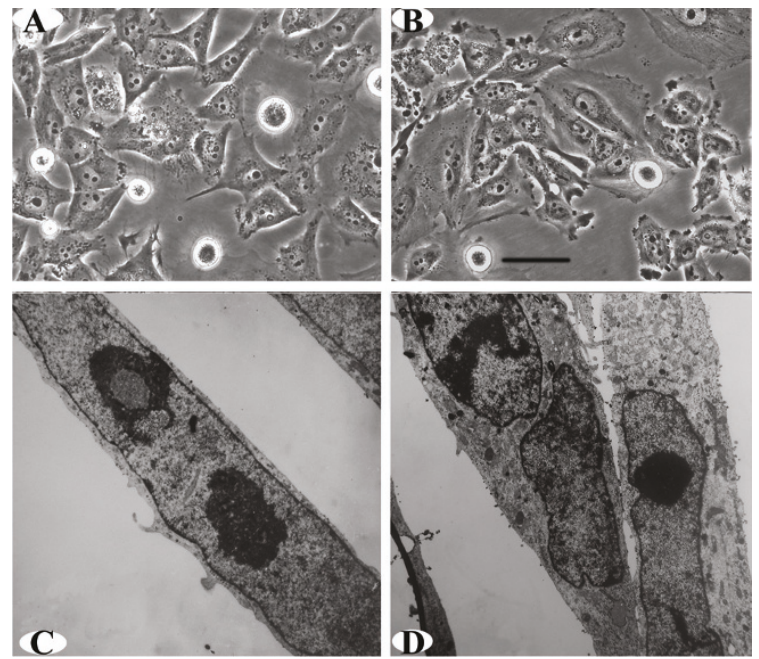

Figure 1. Morphological appearance of Zos and Zos-M cells under light and electron microscopes. (A) Zos cell line. Cell exhibits a polymorphic appearance. Nucleus is atypical and large with 2-3 prominent nucleoli. Karyokinesis is frequent and multiple nuclei can be seen. (B) Zos-M cell line. Cells pile up without growth inhibition. Most of the cells are round or oval with lots of filopodial protrusion and membrane ruffles surrounding the cells. Nucleus is atypical and nucleoli are prominent. Scale bar: $50 \mu \mathrm{m}$. (C) electron microscopic examination of Zos. Spindle-shaped cells with an atypically large nucleus and 2 obvious nucleoli present in the round nucleus. (D) electron microscopic examination of Zos-M. Spindled-shaped cells with 2 nuclei and abundant organelles, including mitochondria and dilated rough endoplasmic reticulum, were seen in the cytoplasm of both Zos and Zos-M. under light microscopy (Figure 1), from spindle to polymorphic, with large nuclei and 2-3 prominent nucleoli. The karyokinesis phase was frequent, and cells with double nuclei and multiple nuclei were seen. Many particles were dispersed in the cytoplasm. The cells grew in a compact pile and exhibited loss of anchorage dependence. Compared to Zos, Zos-M exhibited more filopodial protrusions and membrane ruffles on the cell membrane.

An examination using the transmission electron microscopic revealed polygonal cells with atypical large nuclei and inverted nuclear-cytoplasmic ratios; $2-3$ obvious nucleoli were present in a round nucleus. Abundant organelles, including mitochondria and dilated rough endoplasmic reticulum, were seen in the cytoplasm (Figure 1).

Cell proliferation rate and sensitivity to chemotherapeutic drugs The growth curves for the Zos and Zos-M cell lines were drawn for each cell line (Figure 2A). Both cell lines reached a growth plateau on the sixth day of culture; the saturation density of Zos-M was larger than that for Zos. The population doubling time measured during the logarithmic phase was $33.65 \mathrm{~h}$ for Zos and $31.58 \mathrm{~h}$ for Zos-M.

In order to investigate the sensitivity of Zos and Zos-M to the current chemotherapy drugs compared to U-2OS, the MTT assay were performed and the $\mathrm{IC}_{50}$ value of each drug was calculated (Table 2). There were no statistical differ- 
A

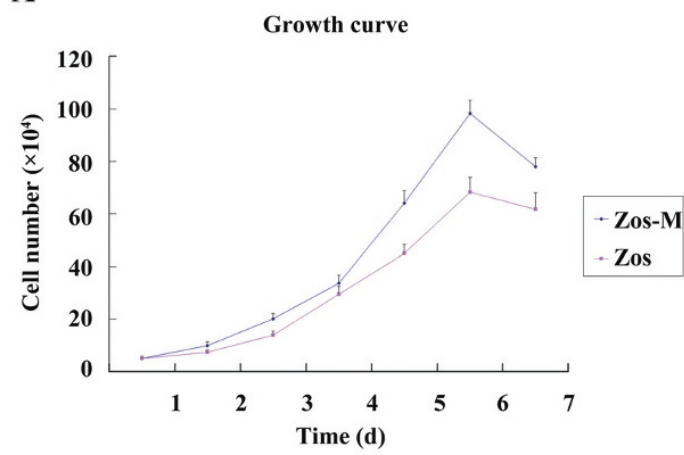

B

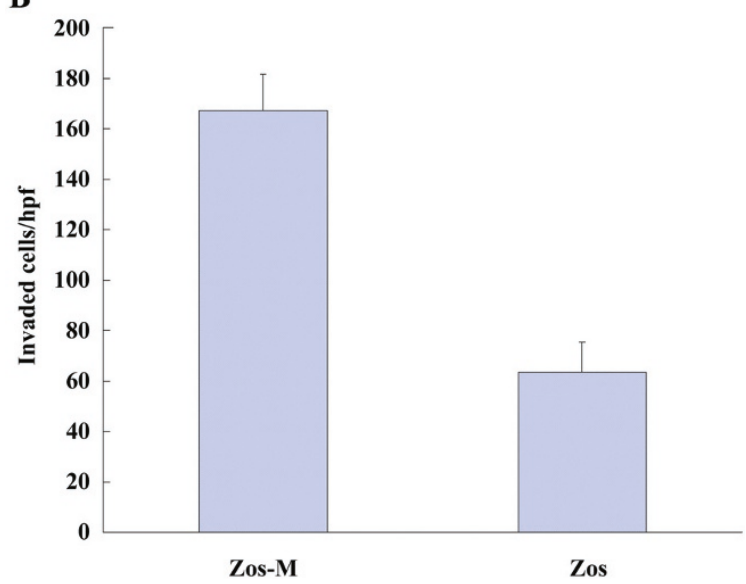

Figure 2. (A) growth curves for Zos and Zos-M. Growth rate of the Zos-M cell line culture exceeded that of the Zos cell line. Doubling time in the logarithmic growth phase of Zos and Zos-M was calculated as 33.65 $\mathrm{h}$ and $31.58 \mathrm{~h}$, respectively. (B) number of Zos and Zos-M cells migrate through the matrigel-coated filter in the transwell chamber after $24 \mathrm{~h}$.

Table 2. Sensitivity of Zos, Zos-M, and U-2OS to anticancer drugs.

\begin{tabular}{lccc}
\hline Cell lines & $\begin{array}{c}\mathrm{MTX} \\
\mathrm{IC}_{50}(\mathrm{ng} / \mathrm{mL})\end{array}$ & $\begin{array}{c}\mathrm{ADM} \\
\mathrm{IC}_{50}(\mathrm{ng} / \mathrm{mL})\end{array}$ & $\begin{array}{c}\mathrm{DDP} \\
\mathrm{IC}_{50}(\mathrm{ng} / \mathrm{mL})\end{array}$ \\
\hline Zos & $15.39 \pm 1.86$ & $14.25 \pm 1.49$ & $437.47 \pm 20.09$ \\
Zos-M & $16.72 \pm 1.72$ & $15.67 \pm 1.36$ & $406.68 \pm 15.84$ \\
U-2OS & $5.71 \pm 0.34$ & $8.17 \pm 1.79$ & $302.17 \pm 21.38$ \\
& & & \\
\hline
\end{tabular}

ence between the chemosensitivity of Zos and Zos-M for all of the drugs tested $(P=0.417$ for MTX; $P=0.289$ for ADM; $P=0.106$ for DDP), although they were more resistant to these drugs than $\mathrm{U}-2 \mathrm{OS}$, the $\mathrm{IC}_{50}$ of which was significant lower $(P<0.01)$.

Tumorigenicity and in vitro and in vivo invasive potential The tumorigenic abilities of Zos and Zos-M were tested by subcutaneous inoculation on the backs of the nude mice. Two months later, tumors formed in the subcutis of all 6 mice for both cell lines. The tumors derived from Zos-M cells were relatively hard, and some osteoid tissues could be seen in the section (Figure 3B); the average size of the tumor reached approximately $2.35 \mathrm{~cm}^{3}$. The tumors derived from Zos expanded quickly, and hemorrhage and necrosis soon occurred; the average volume of the tumor reached $6.77 \mathrm{~cm}^{3}$ within 2 months. Like the original tumor, a rare osteoid could be observed in the histological section (Figure 3A). No evidence of metastases to the major organs was found 2 months after xenotransplantation.

The in vitro invasive potential of Zos and Zos-M was compared by the matrigel invasion assay. Fetal bovine serum was used as a chemoattractant in the bottom chamber. There was nearly a 2.5 -fold increase in the number of invaded cell of Zos-M compared to that of Zos (Figure $2 \mathrm{~B})$. In the experimental metastasis assay, no metastases were found in mice injected with Zos, but 37.5\% (3/8) mice injected with Zos-M developed distant metastases, 2 mice had solitary tumors forming superficially on the lung (Figure 3C), and 1 had bone metastasis in the spine, but no dispersed metastases were found.

Chromosomal analysis Karyotypes of both cell lines were analyzed by Giemsa trypsin banding. Fifteen metaphase cells (excluding polyploid ones) were analyzed for each cell line. The number of chromosomes of the Zos cells ranged from 55 to 60 (mode number was 57). The number of chromosomes of Zos-M cells ranged from 50 to 56 (mode number was 52). The karyotype was very complex and various numerical and structural abnormalities were recognized (Figure 4). Most involved chromosomal abnormalities, including 1p, 1q, 4p, 5p, 11q, 16p, 17p, and 19q. Both cell lines showed alterations of $\operatorname{del}(1)(\mathrm{pter} \rightarrow \mathrm{q} 11:) ; \mathrm{t}(4 ; 5)(\mathrm{q} 28$; $\mathrm{p} 13) ; \mathrm{t}(3 ; 9)(\mathrm{q} 12 ; \mathrm{p} 12)$, and there were also some unidentified marker chromosomes.

Expression of osteoblastic markers and metastasisrelated genes Osteoblast biomarkers were detected in both cell lines; ALP and osteopontin were highly represented, and osteocalcin was relatively weak, but definitely expressed (Figure 5). We compared osteoblasts from the Zos and Zos-M cell lines for the mRNA coding for ezrin, cadherin-11, CD44, Fas, NF2, and BRMS1. Zos-M expressed lower levels of cadherin-11 when compared to Zos (Figure 6). The expression of CD44was detected in hFOB1.19, but not in Zos-M or Zos. Fas could barely be detected in Zos and Zos-M cells, although it was weakly expressed in hFOB1.19. The expression level of ezrin was similar in Zos, Zos-M, and osteoblasts; no differences in the expression of NF2 and BRMS1 were found. 


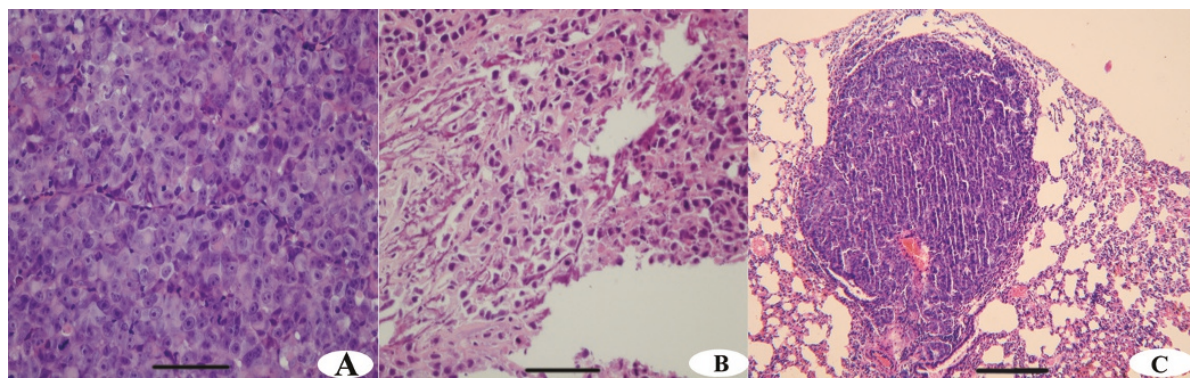

Figure 3. (A,B) histological appearance of the tumor formed 2 months after subcutaneously inoculation near the scapula of nude mice (i: Zos, ii: Zos-M; scale bar: $250 \mu \mathrm{m})$. Zos-M exhibits a more osteoblastic appearance with tumorosteoid compared with Zos cells. (C) histological appearance of metastasis node formed by Zos-M in the lung 8 weeks after intravenous injection (scale bar: $1 \mathrm{~mm}$ ).

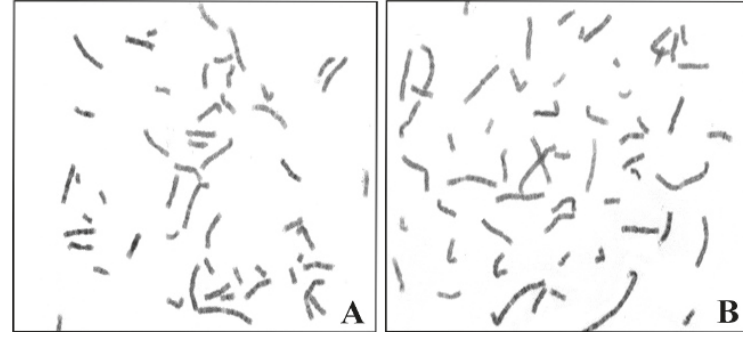

Figure 4. Chromosome assay of Zos and Zos-M. (A) typical karyotype of a Zos-M cell in the 20th generation. Karyotype: 52,X,Y (1)del(1)(pter $\rightarrow \mathrm{q} 11:) ;(2) \operatorname{del}(19)(\mathrm{qter} \rightarrow \mathrm{p} 13:) ;(3) \mathrm{t}(4 ; 5)(\mathrm{q} 28 ; \mathrm{p} 13) ;(4) \mathrm{t}(9 ; 15)(\mathrm{p} 11 ; \mathrm{q} 11) ;$ $(5) \mathrm{t}(3 ; 9)(\mathrm{q} 12 ; \mathrm{p} 12) ;(6) \mathrm{t}(7 ; 9)(\mathrm{q} 11 ; \mathrm{p} 11) ;(7) \mathrm{i}(11)(\mathrm{q} 21) ;(8) \mathrm{t}(1 ; 5)(\mathrm{p} 13 ; \mathrm{p} 13)$; $(9) \mathrm{t}(1 ; \mathrm{x})(\mathrm{q} 25 ; \mathrm{p} 22) ;(10) \mathrm{t}(5 ; 16)(\mathrm{q} 21 ; \mathrm{p} 11)$. (B) typical karyotype of Zos cells in the 23rd generation. Karyotype: $56, \mathrm{X}, \mathrm{Y}(1) \operatorname{del}(1)(\mathrm{pter} \rightarrow$ q12:); (2)del(1)(qter $\rightarrow$ p34:); (3)t(4;5)(q28;p13); (4)t(12;14)(p11;q11); $(5) \operatorname{inv}(9)(\mathrm{p} 11 \mathrm{q} 12) ;(6) \mathrm{t}(\mathrm{x} ; 2)(\mathrm{q} 23 ; \mathrm{p} 11) ;(7) \mathrm{t}(1 ; 11 ; 14)(\mathrm{p} 34 ; \mathrm{q} 32 ; \mathrm{q} 31) ;(8) \mathrm{t}(\mathrm{x} ;$ $1 ; 6)(\mathrm{q} 27 ; \mathrm{p} 32 ; \mathrm{q} 13) ;(9) \mathrm{i}(17 \mathrm{p}) ;(10) \mathrm{t}(2 ; 16)(\mathrm{q} 11 ; \mathrm{p} 11)$

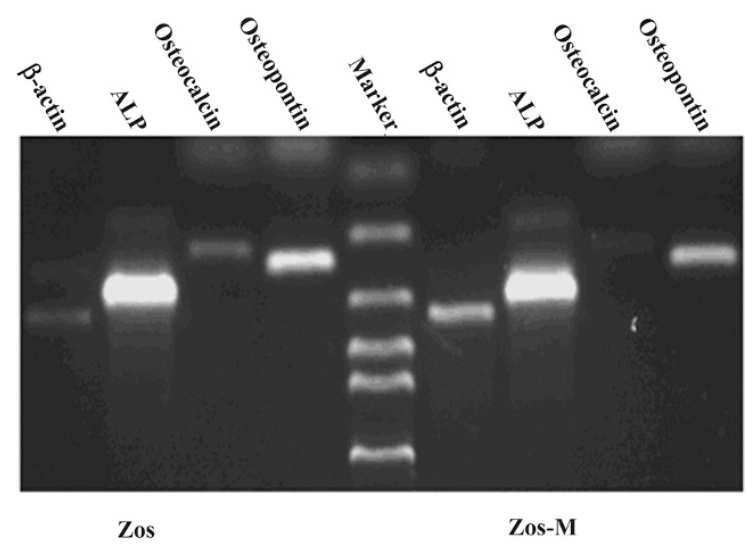

Figure 5. Examination of the expression of osteoblast lineage markers of Zos and Zos-M by RT-PCR. ALP and osteopontin were highly expressed in Zos and Zos-M cells. Osteocalcin was weakly, but definitely expressed in both cell lines.

\section{Discussion}

In the current study, we describe 2 syngeneic cell lines,

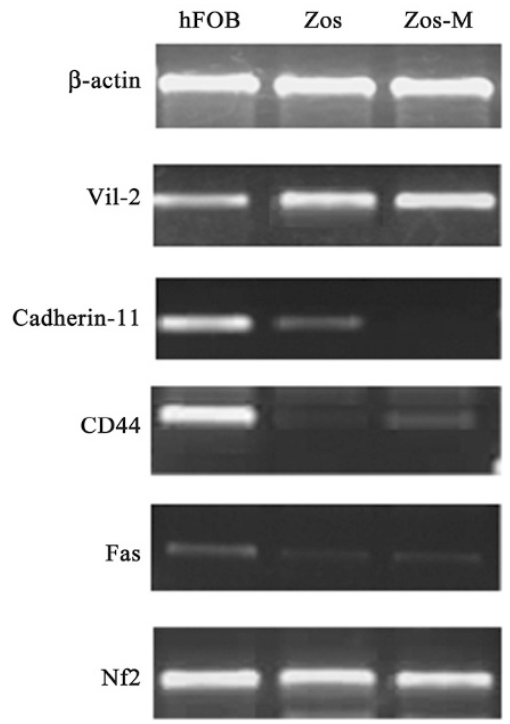

Figure 6. Comparison of the expression of a small panel of metastasis-related genes by RT-PCR. Cadherin-11 was weakly expressed in Zos, while it could hardly be detected in Zos-M cells compared to hFOB1.19. Both CD44 and Fas were weakly expressed in Zos and Zos-M. No difference of ezrin, NF2, and BRMS1 were found among Zos, Zos-M, and osteoblast cells.

Zos and Zos-M. These two cell lines display the molecular characteristics of an osteoblast phenotype. The proliferation assay implies that the cell is in the proliferation-active state and the cells remain stable in culture for 100 passages without interruption. Both Zos and Zos-M are tumorigenic after subcutaneous xenotransplantation in athymic mice. The Zos-M cell line can also develop distant metastases in the lung and bone after intravenous injection. The subcutaneous and lung metastasis masses were similar to the primary tumor in the morphological and immunohistological examinations. All of these indicate that Zos and Zos-M are well-established osteosarcoma cell lines.

The chromosome analyses were consistent with a feature of this tumor that was previously reviewed ${ }^{[17]}$, namely, complex chromosome abnormalities, including a high 
percentage of unidentified marker chromosomes, and pronounced cell-to-cell variation. However, some common chromosome changes could be found between the 2 cell lines, including some commonly involved structural abnormalities described before ${ }^{[17]}$, such as $1 \mathrm{p} 11 \sim \mathrm{p} 13.1 \mathrm{q} 11 \sim \mathrm{q} 12$ and $17 \mathrm{p}$. Until now, no specific diagnostic cytogenetic biomarker has been identified for osteosarcoma, which has led to the retardation in developing molecular diagnoses and gene therapies for osteosarcoma.

The introduction of neoadjuvent chemotherapy dramatically improves the clinical outcome of patients with osteosarcoma. It could benefit the non-metastatic patient at diagnosis, and also could change relapse patterns by delaying the relapse-free interval and reducing the number of metastasis nodals in the lung ${ }^{[18,19]}$. However, for those who relapse with metastases, it is rarely cured. The 5-year survival decreases sharply to $23 \% \sim 28 \%$ for those relapsed patients ${ }^{[20,21]}$. Presumably, these tumors are drug-resistant. Moreover, a study suggested that those who relapse after adjuvant chemotherapy have significantly shorter time for the further progression of disease and shorter survival time compared with those who relapsed after surgery alone ${ }^{[18]}$. Also, the ratio of extrapulmonary metastases increased after the introduction of adjuvant chemotherapy ${ }^{[21]}$, which has a poorer prognosis compared with lung metastasis ${ }^{[22]}$. This means that the osteosarcoma cell that survives the chemotherapy becomes less sensitive to the current protocol and more aggressive than before. In the current study, we found in this patient that the tumor specimen obtained in the surgery had little osteoid tissue and was less differentiated than that of the core needle biopsy. It can be surmised that these changes developed to adapt to the selection pressure of the neoadjuvant chemotherapy. The fact that Zos and Zos-M are more resistant to the drugs than U-2OS, which is established prior to the chemotherapy era, also confirmed the hypothesis. So these cell lines could be interesting models to screen new drugs to surmount chemoresistance.

Skip metastasis is defined as 2 or more discontinuous lesions in the same bone; patients of skip metastases and without other detectable distant metastases are classified as having stage III disease in the recently revised American Joint Committee on Cancer( AJCC )staging system ${ }^{[23]}$. The incidence of skip metastasis ranges from $1.4 \%$ to $25 \%$ in different publications. Dismals outlook were recorded in all reports ${ }^{[2,4-7,24]}$. In a large retrospective investigation, the 5-year survival of patients with skip metastasis is approximately $53 \%$ when the complete surgery resection was achieved and neoadjuvant chemotherapy were performed, which is similar to that of patients with distant metastasis in the same investigation ${ }^{[7]}$. In some other studies, even poorer outlooks were reported. The survival for patients with skip metastasis is significantly less than the survival for patients with pulmonary metastases at presentation ${ }^{[5,6,24]}$. In the current study, we compared the biological behavior of cells from primary and skip lesions. In the case of morphological appearance, Zos-M has more filopodial protrusions and membrane ruffles than Zos, which suggest high motility. The proliferation of Zos-M is more active than that of Zos. Furthermore, Zos-M is more prone to developing lung and bone metastases than Zos after intravenous injection. All of these indicate that the skip metastasis clones may represent the more aggressive one. The chemosensitivity of Zos-M is similar to that of Zos, which is consistent with prior results that identical histological responses to preoperative chemotherapy were observed in primaries and skips $^{[7]}$.

To investigate the different capacity of invasiveness between Zos and Zos-M, the expression of a small panel of metastasis-related genes were analyzed by RT-PCR. The results indicate that the suppression of cadherin- 11 in Zos-M may be involved in the process of dissemination. Cadherin-11 is an adhesion molecule, which mediates homophilic cell-cell adhesion and is significantly expressed in osteoblast cells ${ }^{[25]}$. The suppression of cadherin- 11 in Zos-M may decrease the attachment between the osteosarcoma cells, thus initiating the metastasis process, just as E-cadherin does in the development of carcinoma ${ }^{[26]}$. The same result was also observed by Takeshi ${ }^{[25]}$ with immunohistochemistry: a strong expression of cadherin-11 in normal osteoblasts, but a faint expression in osteosarcoma. They continued to prove using the mouse osteosarcoma cell line that transfection of the cadherin- 11 gene into the high metastasis capacity cell line LM8 leads to the reduction of lung metastasis in vivo ${ }^{[13,25]}$. Therefore, it can be speculated that the decreased expression of cadherin-11 in Zos-M may confer a greater ability of the tumor cell to metastasize.

The results also imply that CD44 are depressed in the Zos and Zos-M cell lines, which is consistent with discoveries in colon cancer cells that the standard form of CD44 acts as a tumor suppressor and inhibits the potential for metastasis ${ }^{[27,28]}$, and in invasive breast cancer patients where CD44 expression may be a favorable prognostic factor $^{[29]}$. Fas, in the presence of FasL, could start the process of apoptosis ${ }^{[30]}$. The poorly-expressed Fas in the Zos-M and Zos cell lines will evade apoptosis in the lung, where FasL is abundantly expressed.

In conclusion, Zos-M and Zos are well-established syn- 
geneic osteosarcoma cell lines with different capacities of invasiveness. Comparisons of gene expression profiles of these 2 cell lines will shed light on the study of intramedullary dissemination of osteosarcoma, and may also provide insight to the investigation of distant metastases. Allowing for the nature of insensitivity to chemotherapy, these 2 cell lines and related animal models would be interesting tools to screen treatment strategies for aggressive osteosarcoma.

\section{Acknowledgements}

We thank Dr M SERRA (Rizzoli institute, Bologna, Italy) for kindly providing the osteosarcoma cell line U-2OS, and Quan-sheng ZHU (MD Anderson Cancer Center, Houston, TX, USA) for linguistic support.

\section{References}

1 Link MP, Eilber F. Pediatric oncology: osteosarcoma. In: Pizzo P A, Poplack DG, editors. Principles and practice of pediatric oncology. Philadelphia: Lippincott; 1989. p 689-711.

2 Bielack SS, Kempf-Bielack B, Delling G, Exner GU, Flege S, Helmke K, et al. Prognostic factors in high-grade osteosarcoma of the extremities or trunk: an analysis of 1,702 patients treated on neoadjuvant cooperative osteosarcoma study group protocols. J Clin Oncol 2002; 20: 776-90.

3 Bruland OS, Pihl A. On the current management of osteosarcoma: a critical evaluation and a proposal for a modified treatment strategy. Eur J Cancer 1997; 33: 1725-31.

4 Enneking WF, Kagan A. The implications of "skip" metastases in osteosarcoma. Clin Orthop 1975; 111: 33-41.

5 Malawer MM, Dunham WK. Skip metastases in osteosarcoma: Recent experience. J Surg Oncol 1983; 22: 236-45.

6 Sajadi KR, Heck RK, Neel MD, Rao BN, Daw N, Rodriguez-Galindo $\mathrm{C}$, et al. The incidence and prognosis of osteosarcoma skip metastases. Clin Orthop Relat Res 2004; 426: 92-6.

7 Kager L, Zoubek A, Kastner U, Kempf-Bielack B, Potratz J, Kotz R, et al. Cooperative Osteosarcoma Study Group. Skip metastases in osteosarcoma: experience of the Cooperative Osteosarcoma Study Group. J Clin Oncol 2006; 24: 1535-41.

8 Berlin O, Samid D, Donthineni-Rao R, Akeson W, Amiel D, Woods VL Jr. Development of a novel spontaneous metastasis model of human osteosarcoma transplanted orthotopically into bone of athymicmice. Cancer Res 1993; 53: 4890-5.

9 Fournierf, B. Price, P.A. Characterization of a new human osteosarcoma cell line OHS-4 J Cell Biol 1991; 114: 577-83.

10 Narita M, Nomura J, Nakase M, Inui M, Murata T, Hamaguchi Y, et al. Characterization of the human mandibular osteoblastic osteosarcoma cell line HOSM-2 after long-term culture. Oral Oncol 2004; 40: $742-50$.

11 Kimura K, Nakano T, Park YB, Tani M, Tsuda H, Beppu Y, et al. Establishment of human osteosarcoma cell lines with high metastatic potential to lungs and their utilities for therapeutic studies on metastatic osteosarcoma. Clin Exp Metastasis 2002; 19: 477-85.

12 Asai T, Ueda T, Itoh K, Yoshioka K, Aoki Y, Mori S, et al. Establishment and characterization of a murine osteosarcoma cell line (LM8) with high metastatic potential to the lung. Int J Cancer 1998; 76: 418 -22 .

13 Kashima T, Nakamura K, Kawaguchi J, Takanashi M, Ishida T, Aburatani $\mathrm{H}$, et al. Overexpression of cadherins suppresses pulmonary metastasis of osteosarcoma in vivo. Int J Cancer 2003; 104: 147-54.

14 Iwaya K, Ogawa H, Kuroda M, Izumi M, Ishida T, Mukai K. Cytoplasmic and/or nuclear staining of beta-catenin is associated with lung metastasis. Clin Exp Metastasis 2003; 20: 525-9.

15 Fukaya Y, Ishiguro N, Senga T, Ichigotani Y, Sohara Y, Tsutsui M, et al. A role for PI3K-Akt signaling in pulmonary metastatic nodule formation of the osteosarcoma cell line, LM8. Oncol Rep 2005; 14: $847-52$.

16 Khanna C, Khan J, Nguyen P, Prehn J, Caylor J, Yeung C, et al. Metastasis-associated differences in gene expression in a murine model of osteosarcoma. Cancer Res 2001; 61: 3750-9.

17 Sandberga AA, Bridgeb JA. Updates on the cytogenetics and molecular genetics of bone and soft tissue tumors: osteosarcoma and related tumors. Cancer Genet Cytogenet 2003; 145: 1-30.

18 Goorin AM, Shuster JJ, Baker A, Horowitz ME, Meyer WH, Link MP. Changing pattern of pulmonary metastases with adjuvant chemotherapy in patients with osteosarcoma: results from the multiinstitutional osteosarcoma study. J Clin Oncol 1991; 9: 600-5.

19 Bacci G, Ferrari S, Longhi A, Perin S, Forni C, Fabbri N, et al. Pattern of relapse in patients with osteosarcoma of the extremities treated with neoadjuvant chemotherapy. Eur J Cancer 2001; 37: 32-8.

20 Kempf-Bielack B, Bielack SS, Jurgens H, Branscheid D, Berdel WE, Exner GU, et al. Osteosarcoma relapse after combined modality therapy: An analysis of unselected patients in the cooperative osteosarcoma study group (COSS). J Clin Oncol 2005; 23: 559-68.

21 Giuliano A, Feig S, Eilber FR. Changing metastatic pattern in osteosarcoma. Cancer 1984; 54: 2160-4.

22 Ferrari S, Briccoli A, Mercuri M, Bertoni F, Picci P, Tienghi A, et al. Postrelapse survival in osteosarcoma of the extremities: prognostic factors for long-term survival. J Clin Oncol 2003; 21: 710-5.

23 Greene FL, Page DL, Fleming ID. AJCC cancer staging manual, 6th ed. New York: Springer-Verlag; 2002.

24 Wuisman P, Enneking WF. Prognosis for patients who have osteosarcoma with skip metastasis. J Bone Joint Surg 1990; 72A: 60-8.

25 Kashima T, Kawaguchi J, Takeshita S, Kuroda M, Takanashi M, Horiuchi $\mathrm{H}$, et al. Anomalous cadherin expression in osteosarcoma possible relationships to metastasis and morphogenesis. Am J Pathol 1999; 155: 1549-55.

26 Pujuguet P, Del Maestro L, Gautreau A, Louvard D, Arpin M. Ezrin regulates E-cadherin-dependent adherens junction assembly through Rac1 activation. Mol Biol Cell 2003; 14: 2181-91.

27 Choi SH, Takahashi K, Eto H, Yoon SS, Tanabe KK.CD44s expression in human colon carcinomas influences growth of liver metastases. Int J Cancer 2000; 85: 523-6.

28 Pereira PA, Rubenthiran U, Kaneko M, Jothy S, Smith AJ. CD44s expression mitigates the phenotype of human colorectal cancer hepatic metastases. Anticancer Res 2001; 21: 2713-7.

29 Diaz LK, Zhou X, Wright ET, Cristofanilli M, Smith T, Yang Y, et al. CD44 expression is associated with increased survival in nodenegative invasive breast carcinoma. Clin Cancer Res 2005; 11: 3309 $-14$.

30 Lafleur EA, Koshkina NV, Stewart J, Jia SF, Worth LL, Duan X, et al. Increased fas expression reduces the metastatic potential of human osteosarcoma cells. Clin Cancer Res 2004; 10: 8114-19. 